\title{
ИСТОЧНИКОВЕДЕНИЕ
}

\author{
УДК 294.321
}

DOI: $10.22162 / 2500-1523-2020-4-824-833$

\section{Фотообразы буддистов Бурятии}

\author{
Андрей Александрович Базаров ${ }^{1}$
}

${ }^{1}$ Институт монголоведения, буддологии и тибетологии СО РАН (д. 6, ул. Сахьяновой, 670047 Улан-У дэ, Российская Федерация); Бурятский государственный университет (д. 24a, ул. Смолина, 670000 Улан-Удэ, Российская Федерация) доктор философских наук, ведущий научный сотрудник, профессор iD 0000-0002-6837-7280.E-mail: bazarow_andr@mail.ru

(C) КалмНЦ РАН, 2020

(C) Базаров А. А., 2020

Аннотация. Цель. Статья посвящена проблеме визуальных образов в повседневной ритуальной практике ординарных буддистов Бурятии. Актуальность изучения раритетных фотографий с буддийским сюжетом в качестве исторического и культурологического источника не вызывает сомнений, поскольку данное исследование раскрывает неизвестные аспекты в формировании идентичности бурят и роли буддизма в этом процессе. Материалом для изучения послужили коллекция редких фотографий Института монголоведения, буддологии и тибетологии Сибирского отделения Российской академии наук и фоторяд ритуального комплекса «хоймор-гунгурба», собранные в ходе экспедиций 50-70-х гг. XX в. и в начале XXI в. Результаты. В ходе предварительных работ был разработан метаязык описания визуальных образов с целью выяснения механизма актуализации данного материала в буддизме в виде следующих пунктов: механизм отбора образов; культурный контекст; ритуальные и социальные цели; характер материалов; учет реакции верующих на визуальные образы. На основе сравнительного анализа двух баз данных автор устанавливает взаимосвязь между местной визуальной практикой буддистов и формированием бурятской идентичности с конца XIX в. до начала XXI в. После сравнительной реконструкции структуры визуальных образов в этой статье утверждается, что культура повседневной практики их почитания является важным аспектом в формировании местной идентичности. Наиболее интересным фактом, обнаруженным в ходе исследования, является то, что в настоящее время центральное место в фото визуальной практике буддистов бурят занимают дореволюционные образы бурятских лам. Анализ подтвердил тот факт, что кардинальное изменение механизма передачи буддийской традиции в Бурятии, социальные сдвиги, экономическая ситуация привели к трансформации вектора развития традиционной буддийской культуры бурят, приоритетом которого становятся на данный момент автокефальные формы, с сохранением своей этнической специфики.

Ключевые слова: буддизм, визуальные образы, фото, коллекция, почитание, буряты, идентичность, повседневная ритуальная практика

Благодарность. Исследование выполнено при финансовой поддержке РФФИ в рам- 
ках научного проекта № 19-09-00068 А «Визуализация повседневной ритуальной культуры в буддизме».

Для цитирования: Базаров А. А. Фотообразы буддистов Бурятии // Монголоведение. 2020. T. 12. № 4. C. 824-833. DOI: $10.22162 / 2500-1523-2020-4-824-833$

UDC 294.321

DOI: $10.22162 / 2500-1523-2020-4-824-833$

\title{
Photo Images of Buryatia's Buddhists
}

\author{
Andrei A. Bazarov ${ }^{1}$
}

${ }^{1}$ Institute for Mongolian, Buddhist and Tibetan Studies, Siberian Branch of the RAS, (6, Sakhyanova St., Ulan-Ude 670047, Russian Federation); Buryat State University (24A, Smolin St., Ulan-Ude 670000, Russian Federation)

Dr. Sc. (Philosophy), Leading Research Associate, Professor

iD 0000-0002-6837-7280. E-mail: bazarow_andr@mail.ru

(C) KalmSC RAS, 2020

(C) Bazarov A. A., 2020

\begin{abstract}
Goals. The paper examines the issue of visual images in the everyday ritual practice of ordinary Buddhists in Buryatia. The relevance of studying rare Buddhist photographs as a historical and cultural source cannot be questioned, since this perspective reveals unknown aspects in the formation of Buryat identity and the role of Buddhism in this process. Materials. The work investigates the collection of rare photographs at the Institute for Mongolian, Buddhist and Tibetan Studies (Siberian Branch of the Russian Academy of Sciences) and photographs of the ritual complex 'khoimor-gungurba' collected during expeditions of the 1950-1970s and in the early $21^{\text {st }}$ century. Results. A method (metalanguage) of describing Buddhist photo images was developed during preliminary works to clarify the mechanism of actualizing this material in Buddhist discourse, including elements as follows: a mechanism of image selection; cultural context; ritual and social goals; nature of materials; registration of believers' reactions to visual images. The paper shows a close relationship between the local visual practice of Buddhists and the formation of Buryat identity from the late $19^{\text {th }}$ towards the $21^{\text {st }}$ century, which is concluded from a comparative analysis of the two databases. After a comparative reconstruction of the structures of the collections, the work argues that the everyday ritual practice of praying before these photos is an important aspect in the formation of local identity. The most interesting finding of the study is that pre-revolutionary images of Buryat Lamas are central in the culture of the photo-visual practices of Buryat Buddhists nowadays. The comparative analysis confirmed that a fundamental change in the transmission of the Buddhist tradition in Buryatia, social changes, and the economic situation led to a change in the development of the traditional Buddhist culture of the Buryats that currently prioritizes autocephaly and the preservation of ethnic identity.
\end{abstract}

Keywords: Buddhism, visual images, photo, collection, worship, Buryat, identity, everyday ritual practice

Acknowledgments. The reported study was funded by RFBR, project no. 19-09-00068 A 'Visual Images of Everyday Buddhist Ritual Culture'.

For citation: Bazarov A. A. Photo Images of Buryatia's Buddhists. Mongolian Studies (Elista). 2020. Vol. 12. No. 4. Pp. 824-833. (In Russ.). DOI: 10.22162/2500-1523-2020-4824-833 


\section{Монголоведение • Mongolian Studies • 2020 ๑ T. 12 • № 4}

\section{Введение}

Визуальные образы в буддизме играют основополагающую роль в повседневных религиозных ритуалах, психосоматической (йогической) практике, а также в распространении ряда конфессиональных представлений. Активная социальная роль буддийской сангхи в Бурятии во все времена формировалась за счет актуализации конкретных образов благодаря картинам (танка, цагли). Начиная с конца XIX в. большую роль в этих действиях начинают играть фотографии. Актуальность изучения раритетных фотографий с буддийским сюжетом в качестве исторического и культурологического источника не вызывает сомнений, поскольку данная научная проблема обращена как к анализу специфических историко-социальных изменений в развитии идентичности бурят на рубеже веков, так и к особенностям использования визуального ряда в современных историко-антропологических исследованиях.

\section{Материалы и методы}

Материалом для исследования послужили коллекция редких фотографий с буддийским сюжетом (далее - ФБС) - монахи, святые места и предметы (250 ед. хр.), хранящаяся в фондах Центра восточных рукописей и ксилографов Института монголоведения, буддологии и тибетологии Сибирского отделения Российской академии наук (ИМБТ СО РАН; коллекция ФБС из этого учреждения далее упоминается как КФБС ИМБТ), и фоторяд (28 фото) комплекса «хоймор-гунгурба» (далее - ФК ХГ). Необходимо отметить, что ФБС в традиционной буддийской культуре региона хранились на северной, «святой», стороне дома (бур. хоймор) верующих буддистов региона в специальном ящике-локусе (бур. гунгурба) 1 и становились частью комплекса «хоймор-гунгурба».

Каков характер материалов? Что касается коллекции ФБС из фондов ИМБТ СО РАН, то ее происхождение связано с экспедиционными работами института в 50-70-е гг. прошлого столетия ${ }^{2}$, поскольку в ней представлены фотографии как дореволюционного периода, так и конца 1960-х гг. ФБС (средний размер экземпляров от 6х9 см до 9х14 см - традиционный размер буддийских миниатюр «цагли») были созданы в фотоателье («Cabinet portreit», «Photographie Borel, St. Petersbourg, Nevsky 54», «Н. А. Чесноковъ, Санкт-Петербургъ», «Т. А. Урсу, Верхнеудинскъ», «Souvenir», «Т-во А. Ф. Второва съ С-ми. Отделение въ Верхнеудинске», «Г. С. Сибирская фотография въ Читъ», «Yu Chang, Peking» и др.) и представляют собой предмет религиозного ежедневного почитания учителей в буддизме (бур. лама тахиха зан үйлэ)․․ Что касается фоторяда комплекса «хоймор-гунгурба», то материалом служат ФБС, которые были собраны в ходе экспедиций ИМБТ СО РАН в период 2019-2020 гг. (частично 2006-2015 гг.). Данный материал ФБС состоит как из фотокопий дореволюционных фотографий, так и из современных открыток, выполненных в типографиях Улан-Удэ и Москвы на рубеже XX-XXI вв.

${ }^{1}$ Данные фотографии широко используются бурятами-буддистами в ежедневной религиозной практике для ритуала почитания учителя, прочтения текста «прибежища», многочисленных заклинаний и подношений и т. п.

2 Это предполагается, поскольку никаких архивных документов о происхождении данной коллекции не было найдено.

${ }^{3}$ В буддийской культуре монгольских народов существуют различные объекты почитания [Бакаева 2019а], «учитель» является одним из главнейших. 


\section{Источниковедение}

В связи с современными тенденциями в гуманитарном знании при анализе подобных визуальных собраний востребованы исторический [Магидов 2005] и социально-антропологический подходы [Anthropology and Photography 1992; Гурьева 2009]. Предлагаемая в данном исследовании методика основывается на системном анализе культур прошлого и настоящего, которые в каждую историческую эпоху проявляют себя на 3-х взаимосвязанных уровнях: 1) на уровне повседневности (ежедневная активность, всевозможные типы регламентации); 2) на уровне идеологии (система символов, отношений и культурно-значимых примеров, через которую формулируются ценности культуры); 3) на уровне социальной организации (внутренние иерархические связи и т. п.). В ходе предварительных работ был разработан метаязык описания визуальных образов с целью выяснения механизма актуализации данного материала в буддизме в виде следующих пунктов:

- механизм отбора образов и отношение к ним;

• всестороннее изучение культурного контекста, в котором эти образы проявляются;

- ритуально-психосоматические цели тех, кто представляет и тех, кто использует образы;

- характер материалов: старые - новые, картины - фото;

• учет реакции потенциальных категорий верующих, визуализирующих образы.

Также для данного исследования был использован метод сравнительного анализа с привлечением инструментов конкретного описания фотоколлекций с религиозным содержанием.

\section{Специфика диахронических изменений в повседневной визуально-ри-} туальной культуре буддистов-бурят

Сравнительный анализ ФБС из КФБС ИМБТ с современным ФК ХГ позволил проследить специфику диахронических изменений в повседневной визуально-ритуальной культуре буддистов-бурят. Какова структурная композиция данных собраний? Анализ показал, что в них зафиксирована ярко выраженная визуальная иерархия, характерная для исторических ситуаций конца XIX - начала XX в., середины XX в. и начала XXI в.

Во главе иерархии представлен прежде всего образ Далай-ламы. В КФБС ИМБТ это образ Далай-ламы ХІІІ Нгаванг Лобсанга Тубтэн Гьяцо (тиб. ngag dbang blo bzang thub bstan rgya mtsho, 1876-1933)4. Данный образ представлен в трех возрастных категориях: молодость (наиболее популярный), зрелость и старость. Поскольку в КФБС ИМБТ этот образ наиболее представительный (38 экземпляров), делается вывод, что данный экземпляр был центральным, начиная с конца XIX в. вплоть до конца 80-х гг. XX в. Эта визуализация фиксируется и в ФК ХГ (1 экз.), т. е. она активна и в наши дни. Несмотря на долгое функционирование, фото Далай-ламы XIII Тубтэна Гьяцо постепенно заменяется фото Далай-ламы XIV Нгаванг Лобсанга Тэнзин Гьяцо (тиб. ngag dbang blo bzang bstan 'dzin rgya mtsho, род. 6 июля 1935 г.). Если в КФБС ИМБТ представлены фотографии молодого Далай-ламы XIV (13 экз.), то в ФК ХГ -

${ }^{4} \mathrm{O}$ значении образа Далай-ламы ХІІІ Нгаванг Лобсанга Тубтэн Гьяцо в истории монгольских народов см. [Богословский 2002]. 


\section{Монголоведение • Mongolian Studies • 2020 ๑ T. 12 • № 4}

в зрелом возрасте (26 экз.). Интересен сюжет фотографий Далай-ламы XIV. Фотографии из КФБС ИМБТ являются самостоятельными фотокопиями из советских журналов и газет. На них изображен Далай-лама XIV отдельно (6 экз.) и совместно с Панчен-ламой X (7 экз.). Все фотографии являются официальными и связаны с общественно-политическими событиями на территории КНР, т. е. до 1959 г. Фотографии из ФК ХГ напечатаны в типографиях. Основная часть (20 экз.) фиксирует Далай-ламу отдельно, остальные (6 экз.) совместно с Пандито хамбо-ламой XXIII Чой-Доржи (Александром Нимбуевичем) Будаевым (род. в 1959 г.). Вторым по значимости является образ Панчен-ламы. В КФБС ИМБТ это прежде всего образ Панчен-ламы IX Тубтэн Чокьи Ньимы (тиб. thub bstan chos kyi nyi ma, 1883-1937), представленный в двух возрастных категориях: молодость (5 экз.) и зрелость (2 экз.). Что касается ФК ХГ, то здесь этот образ не встречается. Фото Панчен-ламы Х Лобсанг Тринле Лхундруп Чокьи Гьялцена (тиб. blo bzang phrin las lhun grub chos kyi rgyal mtshan, 1938-1989) в молодом возрасте (4 экз.) обнаружены в КФБС ИМБТ (не считая 7 экз. совместно с Далай ламой XIV). В ФК ХГ фотографии Панчен-ламы Х отсутствуют, а также и Панчен-ламы XI. Следующий образ в визуальной иерархии буддистов региона связан с Богдо-гэгэнами. В КФБС ИМБТ обнаружены фото Богдо-гэгэна VIII Нгаванг Лобсанг Чокьи Ньима Тензин Вангчуга (монг. агваан лувсан чойжсин ням данзан ванчүг, тиб. ngag dbang blo bzang chos kyi nyi ma bstan 'dzin dbang phyug; 1869-1924)'. Его образ зафиксирован в нескольких вариантах: в молодом (11 экз.) и зрелом возрасте (2 экз.). Фотографии в зрелом возрасте являются парными: Богдо-гэгэн VIII сфотографирован с женой Цэндийн Дондогдулам (монг. Улсын эх дагина 'Мать-дакини государства', 18761923). На двух фотографиях его супруга изображена в одиночестве. На одном экземпляре обнаружена подпись «Белая Тара» на бурятском языке. В ФК ХГ образ Богдо-гэгэнов представлен 1 фотографией Богдо-гэгэна VIII. Фотообразы последующих перерожденцев этой линии преемственности в данной коллекции найти не удалось.

Следующая группа фотографий в визуальной иерархии бурятского буддизма представляет тибетских и монгольских учителей. В КФБС ИМБТ хранятся фото знаменитых представителей буддийских монастырей Тибета и Монголии, посетивших Бурятию на рубеже XIX-XX вв., а также имевших духовную связь с бурятами в этот период. Это представители монастыря Лавран Ташичил (тиб. bla brang bkra shis 'khyil): Кунчен Джамьян Шэпа IV Келсанг Тубден Ванчуг (тиб. kun mkhyen 'jam dbyangs bzhad pa skal bzang thub bstan dbang phyug, 1856-1916) в детстве (1 экз.) и молодости (1 экз.); Кунчен Джамьян Шэпа V Лобсанг Джамьян Еше Тенпе Гьялцэн (тиб. kun mkhyen 'jam dbyangs bzhad pa blo bzang 'jam dbyangs ye shes bstan pa'i rgyal mtshan, 1916-1947) в детстве (1 экз.); Гунтан Джамьян Тенпе Нима V (тиб. gung thang 'jam dbyangs bstan pa'i nyi ma, 1860-1925) в пожилом возрасте (2 экз.). Представитель другого тибетского монастыря Гумбум, шестьдесят девятый Гумбум-тичен (тиб.

\footnotetext{
${ }^{5}$ О роли Богдо-гэгэна VIII в формировании монгольской этнической идентичности см. [Кузьмин, Оюунчимэг 2009].

${ }^{6}$ Возможно, буряты рассматривали в качестве Белой Тары любую правительницу, не только правительниц России. В результате значение олицетворения российской царской власти с образом Белой Тары для бурятской культуры не следует преувеличивать.
} 


\section{Источниковедение}

sku 'bum khri chen) Джаягсы-гэгэн Келсанг Цултим Тэн Нима (тиб. rgya yag mkhan chen skal bzang tshul khrim bstan nyi ma, 1858-1913) в молодости (2 экз.) и зрелости (7 экз. $)^{7}$. Булганский монастырь в Монголии представлен в коллекции фотографиями монгольского монаха, известного в бурятском буддизме под именами Гашой-лама Дамби-Жамса и Шераб Гьяцо ${ }^{8}$, годы жизни неизвестны (10 экз.). В коллекции хранятся фотографии тибетских и монгольских монахов, имена которых известны, но исторической информации по ним нет: Лобсанг Жампа Зангпо (1 экз.), Милаггшин-гэгэн (3 экз.), Акпа-лама (1 экз.), Дара-эхэ-лама (1 экз.), Ургинский Гашой-лама (1 экз.). В ФК ХГ тибетские учителя представлены исключительно современными образами Кушок Бакулы Ринпоче (1917-2003) в пожилом возрасте (3 экз.), Ело Тулку Еше Лодоя Ринпоче (тиб. ye blo sprul sku ye shes blo gros rin po che, род. в 1943 г.) в зрелом возрасте (2 экз.). Монгольские учителя в коллекции не представлены. Фотографии тибетских и монгольских монахов рубежа XIX-XX вв. отсутствуют.

В иерархической структуре визуальных образов следующей группой являются фото представителей бурятского буддизма:

- $\quad$ перерожденцы;

- Пандито хамбо-ламы;

- $\quad$ настоятели монастырей и известные религиозные деятели.

В КФБС ИМБТ присутствуют фотографии следующих лиц:

- Ганжурва-гэгэна VI Данзана Норбоева (1887-1935) (1 экз.);

- Пандито хамбо-ламы Х Дампил Гомбоева (1831-1896) (1 экз.);

- Пандито хамбо-ламы Чойнзон-Доржи Иролтуева (1843-1918) (2 экз.);

- Пандито хамбо-ламы XV Цыгунжапа Баниева (?) (1 экз.);

- Пандито хамбо-ламы XVII Лубсан-Нимы Дарма́ева (1890-1960) (1 экз.);

- Пандито хамбо-ламы XVIII Еши-Доржи Шарапова (1892-1976) (1 экз.);

- Агван-Лобсана Доржиева (1853-1938) (3 экз. $)^{9}$;

- Лубсан-Сандана Цыденова (1841-1922) (1 экз.);

- Тугулдура Тобоева (?) (1 экз.);

- $\quad$ настоятеля Баргузинского дацана Цыдена Соодоева (6 экз.); настоятеля Анинского дацана Жамбаева (5 экз.);

- настоятеля Эгитуйского дацана Соржи-ламы Чойжи-Лобсан Гомбо-Дорже Эрдынеева (5 экз.);

- настоятеля Эгитуевского дацана Дашапыла Зодбоева (4 экз.);

- настоятеля Тугнуй-Галтайского дацана Чагдаржапа Донсорунова (2 экз.);

- настоятеля Цугольского дацана Галсаа-Тарба Иванова (1 экз.);

- настоятеля Агинского дацана Дарижапа Норбоева (1 экз.);

- настоятеля Анинского дацана Аюши Абидуева (4 экз.).

Что касается ФК ХГ, то в этой коллекции можно обнаружить фото:

- Ганжурва-гэгэна VI Данзана Норбоева (2 экз.);

- Пандито хамбр-лаамы Х Дампила Гомбоева (1831-1896) (2 экз.);

${ }^{7}$ О роли Джаягсы-гэгэна Келсанг Цултим Тэн Нимы в истории бурятского буддизма см. [Лепехов 2012].

${ }^{8}$ О Гашой-ламе Дамби-Жамса см. [Дарибазарон 2018].

9 О роли Агван-Лобсана Доржиева в истории российского буддизма см. [Андреев 2006]. 


\section{Монголоведение • Mongolian Studies • $2020 \bullet$ T. 12 • № 4}

- Пандито хамбо-ламы XII Даши Доржо Итигэлова (1852-1927) $(18 \text { экз. })^{10}$;

- Агван-Лобсана Доржиева (1853-1938) (5 экз.);

- Лубсан-Сандана Цыденова (1841-1922) (2 экз.);

- настоятеля Баргузинского дацана Цыдена Соодоева (7 экз.);

- $\quad$ настоятеля Анинского дацана Жамбаева (1 экз.);

- настоятеля Эгитуйского дацана Соржи-ламы Чойжи-Лобсан Гомбо-Дорже Эрдынеева (1 экз.);

- настоятеля Эгитуйского дацана Дашапыла Зодбоева (1 экз.);

- настоятеля Тугнуй-Галтайского дацана Чагдаржапа Донсорунова (3 экз.);

- $\quad$ настоятеля Анинского дацана Аюши Абидуева (2 экз.).

Сравнительный анализ двух баз данных (КФБС ИМБТ и ФК ХГ), распределенных на три группы: буддийские иерархи, тибетские и монгольские учителя, бурятские ламы, позволил проследить интересные изменения, происходящие в визуальной практике буддистов бурят в период с конца XIX до начала XXI вв.

Анализ образа буддийских иерархов показал, что изображения Далай-лам устойчиво занимают центральное место в визуальной иерархии буддистов региона на протяжении всего периода. Необходимо отметить, что вплоть до 7080-х гг. ХХ в. данный образ был в основном связан с фотографией Далай-ламы XIII, жившего до 1933 г. Такая продолжительность распространенности данного образа объясняется фактическим отсутствием связи бурятских буддистов с Далай-ламой XIV до конца 1980-х гг. Отдельные фотографии Далай-ламы XIV, появляющиеся в практике 1960-1970-х гг., являются любительскими фотокопиями китайской официальной прессы 1950-х гг. Начиная с 1990-х до настоящего времени фотообраз Далай-ламы XIV обладает наибольшим значением для местных буддистов, что можно заключить исходя из количества экземпляров. Что касается образа Панчен-лам и Богдо-гэгэнов (Панчен-ламы IX и Х, Богдо-гэгэн VIII), то судьба их во многом похожа. Если до 19701980-х гг. данные образы еще присутствуют в ритуальной практике, то после 1990-х гг. они резко исчезают. Характерно, что изображение Богдо-гэгэна VIII в виде 1 экземпляра фотографии было найдено в ФК ХГ. Тем не менее, можно утверждать, что данный образ фактически исчез. Исчезновение этих образов объясняется запутанностью религиозно-политической ситуации относительно признания перерожденцев данных линий преемственности в настоящее время.

Обращение к визуальным образам тибетских и монгольских учителей позволило сделать ряд интересных историко-социальных умозаключений. Необходимо подчеркнуть, что буддисты в Бурятии в период с конца XIX в. до 70-80-Х гг. XX в. строили свою общину (в Российской империи и советском государстве) в весьма сложных условиях государственного давления, направленного на достижение полного управленческого унитаризма и унификацию населения ${ }^{11}$. Они прекрасно осознавали свое маргинальное положение в стране, свою культурную инаковость и чуждость основному направлению государственного развития (православного и коммунистического). Вероятно, в этих

${ }^{10}$ О месте Даши Доржо Итигэлова в современном буддизме Бурятии см. [Амоголонова 2012].

${ }^{11}$ О проблеме взаимодействия царской власти и буддийской общины Бурятии в Российской империи на рубеже XIX-XX вв. см. [Цыремпилов 2013]. 


\section{Источниковедение}

условиях ординарное буддийское население рассматривает фото тибетских и монгольских монахов не только как образ буддийского учителя, распространяющего учение [Нацов 1995; Нацов 1998] и объект для ежедневной ритуальной практики, но и как основу собственной религиозной и этнической идентичности. Вероятно, этот фактор повлиял на массовое распространение данных фото $^{12}$, когда вопрос о бурятской идентичности в конце XIX в. стал острым. Также необходимо заметить, что царский запрет на проповедническую деятельность иностранных религиозных деятелей на территории Восточной Сибири бурятской буддийской общиной фактически игнорировался с конца XIX в. Материалы свидетельствуют, что приглашенные в этот период бурятами тибетские и монгольские монахи переходили границу и распространяли буддийское учение, становясь на долгие годы объектом визуальной практики местных буддистов, вплоть до 70-80-х гг. XX в. Что касается ситуации после 1990-х гг., образы тибетских и монгольских учителей рубежа XIX-XX вв. постепенно исчезли (особенно монгольские). Несмотря на бурную проповедническую деятельность многочисленных тибетских монахов на рубеже XXXXI вв. в связи с социально-политическими изменениями в России, их образы практически отсутствуют в ритуальной практике местного буддизма. Это не касается только двух лиц: Кушок Бакулы Ринпоче и Еше Лодоя Ринпоче, фотообразы которых были обнаружены в небольшом количестве в ФК ХГ. Интересный факт связан с тибетским наставником Джампа Тинлей Вангченом (род. в 1962 г.), основателем общины «Зеленая Тара» и популярным буддийским учителем в Бурятии: его образ не был найден вообще.

Сравнительный анализ двух баз данных показал, что на рубеже XXXXI вв. центральное место в визуальной практике буддистов бурят начинают занимать образы бурятских лам. В основном, в местном буддизме прослеживаются ретроспективные формы отбора образов. Точка зрения «Буддийской традиционной сангхи России» (далее - БТСР) играет главную роль в этом механизме. В дальнейшем официальная позиция БТСР относительно образов ретранслируется через систему монастырей до каждого буддиста-мирянина. В результате буддисты-буряты в отборе фото большое значение придают бурятским ламам прошлого или недавнего прошлого. Так, например, наиболее значимым местным образом становится фотография Пандито хамбо-ламы XII Даши Доржо Итигэлова. Он в определённой степени начинает соперничать с образом Далай-ламы XIV. Образы бурятских лам прошлого (рубежа XIXXX вв.) все чаще занимают место тибетских и монгольских учителей, особенно это касается изображений Агвана Доржиева, Данзана Норбоева, Цыдена Соодоева, Лубсан-Сандана Цыденова и многих других, прежде всего настоятелей местных монастырей. Большое значение придается образам местных лам, работавших с населением в 1940-1980 гг. Что касается современных бурятских монахов, то набор образов ограничен фотографиями родственников и односельчан - священнослужителей и учеников монастырей, открыткой с изображением Пандито хамбо-ламы XXIII Чой-Доржи Будаева (с совместного фото с Далай-ламой XIV). Образ современного Пандито хамбо-ламы XXIV Дамбы Аюшеева в системе отсутствует.

${ }^{12} \mathrm{O}$ связи этнической идентичности монголоязычных народов России и тибетского буддизма см. [Бакаева 2019б]. 


\section{Монголоведение • Mongolian Studies • 2020 ๑ T. 12 • № 4}

\section{Выводы}

Что касается изменений, произошедших в 90-х гг. прошлого столетия, необходимо подчеркнуть, что определение локальной идентичности бурят-буддистов подразумевает анализ разных аспектов их мировоззрения, культурной жизни, исторического прошлого [Жуковская 2008]. Буддийская визуальная практика в повседневных ритуалах ординарных буддистов является важнейшим аспектом в формировании местной идентичности в современных условиях. Фотографические образы играют значительную роль в данной практике. Сравнительный анализ двух собраний фотообразов подтвердил тот факт, что кардинальное изменение механизма передачи буддийской традиции в Бурятии, социальные сдвиги, экономическая ситуация привели к трансформации вектора развития традиционной буддийской культуры бурят, приоритетом которого становятся на данный момент автокефальные формы с сохранением своей этнической специфики.

Необходимо подчеркнуть, что рассмотрение интереснейших фотоколлекций из фондов ИМБТ СО РАН на основе методов сравнительно-исторического анализа позволяет исследовать не только ранее неизвестные исторические факты, выявить специфику историко-социальных изменений, но и оценить возможности использования визуального ряда в современных историко-антропологических исследованиях.

\section{Литература}

Амоголонова 2012 - Амоголонова Д. Д. Возвращение Хамбо-ламы Итигэлова в контексте постсоветской десекуляризации общественного сознания // Tartaria Magna. 2012. № 1. С. 128-147.

Андреев 2006 - Андреев А. И. Тибет в политике царской, советской и постсоветской России. СПб.: СПбГУ; Нартанг, 2006. 464 с.

Бакаева 2019а - Бакаева Э. П. Буддизм калмыков и ойратов: обряды подношений предкам и духам хозяевам территорий (некоторые аспекты) // Труды института востоковедения РАН. ВЫп. 23. М.: ИВ РАН. 2019. С. 39-66.

Бакаева 20196 - Бакаева Э. П. Этническая идентичность калмыков и конфессиональные связи с Тибетом (к прочтению малоизвестных источников) // Oriental Studies. 2019. № 5. С. 891-925.

Богословский 2002 - Богословский В. А. Политика ХІІІ Далай-ламы в Тибете. М.: ИВ PAH, 2002. $141 \mathrm{c}$.

Гурьева 2009 - Гурьева М. М. Повседневная фотография как объект научного исследования // Вестник Ленинградского гос. ун-та им А. С. Пушкина. Серия философия. № 3 (2). 2009. С. 153-161.

Дарибазарон 2018 - Дарибазарон Д. Э. «Нектар устных наставлений» Лобсанг Тенпе Гьяцо как источник буддийской философской мысли в Бурятии на рубеже XIXХX вв.: дис. ... канд. ист. наук. Улан-Удэ, 2018. 239 с.

Жуковская 2008 - Жуковская Н. Л. Буддизм и шаманизм как факторы формирования бурятского менталитета // Религия в истории и культуре монголоязычных народов России. М.: Вост. лит., 2008. С. 9-37.

Кузьмин, Оюунчимэг $2009-$ Кузьмин С. Л., Оюунчимэг Ж. Богдо-гэгэн VIII - великий хан Монголии // Азия и Африка сегодня. 2009. № 1. С. 59-64.

Лепехов 2012 - Лепехов С. Ю. Б. Д. Дандарон - буддолог, тибетолог, философ // Вестник Бурятского научного центра СО РАН. 2012. № 3 (7). С. 259-266. 


\section{Источниковедение}

Магидов 2005 - Магидов В. М. Кинофотофонодокументы в контексте исторического знания. М.: РГГУ, 2005. 393 с.

Нацов 1995 - Нацов Г.Д. Материалы по истории и культуре бурят / введ., пер. и примеч. Г. Р. Галдановой. Ч. І. Улан-Удэ: БНЦ СО РАН, 1995. 156 с.

Нацов 1998 - Нацов Г.Д. Материалы по ламаизму в Бурятии / предисл., пер., примеч. и глоссарий Г. Р. Галдановой. Ч. ІІ. Улан-Удэ: БНЦ СО РАН, 1998. 187 с.

Цыремпилов 2013 - Цыремпилов Н. В. Буддизм и империя: бурятская буддийская община в России (XVIII - нач. XX в.). Улан-Удэ: ИМБТ СО РАН, 2013. 338 с.

Anthropology and Photography 1992 - Anthropology and Photography, 1860-1920 / ed. by Elizabeth Edwards. N. Haven, London: Yale University Press. 1992. 288 p.

\section{References}

Amgolonova D. D. Khambo Lama Itigelov's return in the context of post-Soviet desecularization of public consciousness. Tartaria Magna. 2012. No. 1. Pp. 128-147. (In Russ.)

Andreev A. I. Russia and Tibet: A History of Tsarist, Soviet and Post-Soviet Policy. St. Petersburg: St. Petersburg State University, Narthang, 2006. 464 p. (In Russ.)

Bakaeva E. P. Ethnic identity of the Kalmyks and confessional ties with Tibet: a case study of some little-known sources. Oriental Studies. 2019. No.5. Pp. 891-925. (In Russ.) DOI: 10.22162/2619- 0990-2019-45-5-891-925

Bakaeva E. P. The Buddhism of Kalmyks and Oirats: rituals of offerings to the ancestral spirits and the spirits - masters of the territories (some aspects). Proceedings of the Institute of Oriental Studies of RAS. 2019. Is. 23. Pp. 39-66. (In Russ.)

Bogoslovsky V. A. Policy of the $13^{\text {th }}$ Dalai Lama in Tibet. Moscow: Institute of Oriental Studies (RAS), 2002. 141 p. (In Russ.)

Daribazaron D. E. Nectar of Oral Instruction by Lobsang Tenpe Gyatso as a Source of Buddhist Philosophical Thought in Buryatia at the Turn of the $20^{\text {th }}$ Century. Cand.Sc. (history) thesis. Ulan-Ude, 2018. 239 p. (In Russ.)

Edwards E. (ed.) Anthropology and Photography, 1860-1920. New Haven, London: Yale University Press, 1992. 288 p. (In Eng.)

Gourieva M. M. Scientific evaluation of everyday photography. Pushkin Leningrad State University Journal. 2009. No. 3(2). Pp.153-161. (In Russ.)

Kuzmin S. L., Oyuunchimeg J. $8^{\text {th }}$ Bogdo-Gegen - the Great Khan of Mongolia. Asia and Africa Today. 2009. No. 1. Pp. 59-64. (In Russ.)

Lepekhov. S. Yu. B. D. Dandaron - Buddhist scholar, Tibetologist, Philosopher. Bulletin of the Buryat Scientific Center of the Siberian Branch of the RAS. 2012. No. 3 (7). Pp. 259266. (In Russ.)

Magidov V. M. Film, Photo, and Phono Documents in the Context of Historical Knowledge. Moscow: Russian State University for the Humanities, 2005. 393 p. (In Russ.)

Natsov G. D. Materials on Lamaism in Buryatia. Part II. G. Galdanova (foreword, transl., etc.). Ulan-Ude: Buryat Scientific Center (Sib. Branch of RAS), 1998. 187 p. (In Russ.)

Natsov G. D. Materials on the history and culture of the Buryats. Part I. G. Galdanova (foreword, transl., etc.). Ulan-Ude: Buryat Scientific Center (Sib. Branch of RAS), 1995. 156 p. (In Russ.)

Tsyrempilov N. V. Buddhism and Empire: Buryat Buddhist Community in Russia $\left(18^{\text {th }}-\right.$ Early $20^{\text {th }}$ Century). Ulan-Ude: Institute for Mongolian, Buddhist and Tibetan Studies (Sib. Branch of RAS), 2013. 338 p. (In Russ.)

Zhukovskaya N. L. Buddhism and shamanism as factors in the shaping of Buryat mentality. In: Religion in the History and Culture of Russia's Mongolic Peoples. Moscow: Vostochnaya Literatura, 2008. Pp. 9-37. (In Russ.) 